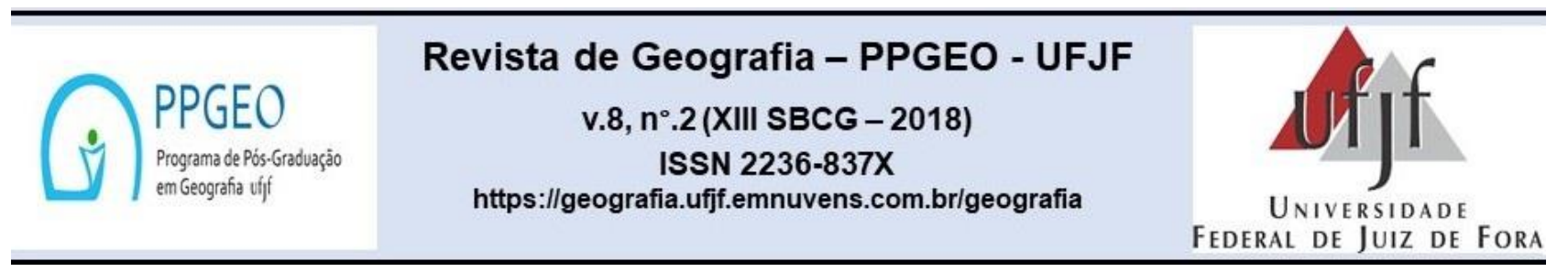

\title{
DIALOGANDO COM ENSINO DE CLIMATOLOGIA E A PRÁTICA DIDÁTICA NA GEOGRAFIA
}

\section{DIALOGUE WITH TEACHING OF CLIMATOLOGY AND THE PRACTICE TEACHING IN GEOGRAPHY}

HUGO LEVY DA SILVA DE MELO

Instituto de Geociências da Universidade Estadual de Campinas

R. Carlos Gomes, 250 - Cidade Universitária, Campinas - SP, 13083-851

E-mai: hugo-am@hotmail.com

Rafael Vinicius De São José

Instituto de Geociências da Universidade Estadual de Campinas

R. Carlos Gomes, 250 - Cidade Universitária, Campinas - SP, 13083-851

E-mail: rafauniversitario16@hotmail.com

Kezia Andrade Dos Santos

Instituto de Geociências da Universidade Estadual de Campinas

R. Carlos Gomes, 250 - Cidade Universitária, Campinas - SP, 13083-851

E-mai: keziapeniel@gmail.com

ROBERTO GRECO

Instituto de Geociências da Universidade Estadual de Campinas R. Carlos Gomes, 250 - Cidade Universitária, Campinas - SP, 13083-851

E-mail: greco@ige.unicamp.br

\section{Informações sobre o Artigo}

Data de Recebimento:

Novembro/2018

Data de Aprovação:

Dezembro/2018

\begin{abstract}
Resumo
O ensino da Geografia Física e principalmente 0 de Climatologia, necessitam de estudos que proporcionem resultados que auxiliem os professores a transformar os fenômenos complexos do clima, em aulas interessantes e que oportunize ao aluno o pensar e refletir criticamente elementos climáticos que os rodeiam. Assim, buscamos como objetivo concretizar o processo de ensino-aprendizagem da climatologia dentro do ensino de geografia. Para esse processo foram confeccionados materiais didáticos (Anemômetro e Barômetro)
\end{abstract} para que pudessem entender os processos naturais de formação e atuação dos elementos do clima. A prática foi realizada com os alunos do 6ํำ do ensino fundamental, e com as aulas ministradas e observações feitas notou-se uma melhor compreensão dos discentes sobre os conteúdos teóricos de climatologia repassados no ensino fundamental.

Palavras-chave: Climatologia, Ensino-Aprendizagem de Geografia, Material didático.

\begin{abstract}
The teaching of Physical Geography and especially the Climatology, need studies that provide results that help teachers to transform complex phenomena of the climate, interesting lessons and that allows the student to think and reflect critically climatic elements that surround them. Thus, we aim to concretize the teachinglearning process of climatology within the teaching of geography. For this process were made didactic materials (Anemometer and Barometer) so that they could understand the natural processes of formation and performance of the elements of the climate. The practice was carried out with the students of the 6th grade, and with the classes given and observations made it was noticed a better understanding of the students about the theoretical contents of climatology passed on in elementary school.
\end{abstract}

Keywords: Climatology, Geography Teaching-Learning, Didactic material. 


\section{Introdução}

O conhecimento sobre o clima é de extrema importância em razão de sua influência na vida do ser humano, com repercussões em diversas atividades econômicas, refletindo na qualidade de vida.

Nota-se que as discussões relacionadas ao clima têm ganhado, cada vez mais, posição de destaque na sociedade, sobretudo no âmbito científico e na mídia de comunicação, uma vez que, em diversos locais da Terra, fenômenos climáticos têm causados desastres naturais, resultando em impactos econômicos e sociais, comprometendo, assim, o bem-estar do ser humano.

No entanto, quanto ao ensino de clima na Educação Básica, a relevância do seu estudo é comumente ignorada pelos alunos, e às vezes, pelo próprio docente. Acredita-se que isso pode estar atrelado a forma como esse conteúdo é ensinado, muitas vezes, a partir de uma abordagem tradicional e sem significância para a vida cotidiana dos alunos.

$\mathrm{Na}$ perspectiva de Oliveira et. al (2010, p. 47), isso "limita a capacidade do discente em contextualizar e enxergar os conteúdos na prática. Também enfatiza que a abordagem dos conteúdos de Climatologia nas escolas públicas tem apresentado um saber descontextualizado, dado que são trabalhados de forma estática, sem relação com os saberes dos alunos e com o seu dia a dia. Para desconstruir essa visão torna-se necessário estratégias metodológicas voltadas para um ensino de qualidade, que nesse caso, consiste em aproximar esse conteúdo da realidade dos alunos, tornando as aulas mais criativas, interativas e prazerosas.

Tendo em vista esse contexto, foi pensada a realização de uma prática na qual foram confeccionados materiais didáticos (Anemômetro e Barômetro) construídos para facilitar o entendimento dos processos naturais de formação e atuação dos elementos do clima.

Portanto, este artigo prende-se a preocupações e questionamentos surgidos a partir da identificação de problemas de compreensão por parte dos alunos do ensino fundamental, no que tange aos conhecimentos do clima abordados na Escola. Dessa maneira buscamos como objetivo concretizar o processo de ensino-aprendizagem da climatologia dentro do ensino de geografia, como uma forma didática diferenciada com o intuito de tornar os conteúdos climáticos mais atrativos e esclarecedores.

\section{Materiais e Métodos}

Os dados que serão apresentados a seguir são resultados do exercício práticos com alunos de $6^{\circ}$ ano, tendo como foco principal proporcionar ao estudante de ensino fundamental a compreensão do clima a partir de ações concretas de percepção de mudança do tempo dentro e fora da sala de aula. 
Desse modo, apresentamos aos alunos atividades que foram divididas em duas etapas. A primeira: como funcionam os principais instrumentos para a coleta de informações referente à atmosfera, tempo e a climatologia através de vídeos, slides e elaboração de instrumentos climáticos pelos próprios alunos. A segunda atividade, que depois de aplicada nesta prática diferenciada, serviram para os alunos interpretarem o tempo no seu dia a dia através de sua percepção e sensibilidade: classificação das "mudanças meteorológicas" existentes na escola por meio da observação sensível.

\section{Referencias bibliográfica}

Há bastante tempo o homem se interessa pelas mudanças que ocorrem no nosso planeta, à curiosidade a respeito do que nos rodeia é algo bastante natural, pois compreender as transformações que modificam ou influenciam nossas vidas se fazem necessárias na busca de esclarecer dúvidas e inquietações construídas em nossa mente. Dentre as inquietações estão os estudos do clima no qual ocupa uma posição muito importante no campo das ciências, pois os processos atmosféricos influenciam de forma direta as mudanças do ambiente terrestre.

No que tange a área de educação quanto ao ensino de climatologia, fica a cargo da Geografia que dentre os seus conteúdos do ensino fundamental estão inseridos os conceitos climatológicos. Porém, muita das vezes têm sido negligenciado por professores, ou realizado de forma fragmentada, enciclopédica e dissociada do cotidiano dos alunos.

Vale ressaltar, que a geografia é uma disciplina que integra contribuições de todos os campos do saber, uma vez que focaliza temas relacionados à sociedade e à natureza. Nessa perspectiva, a climatologia surge como uma área específica de conhecimento dentro da geografia, na qual Mendonça e Danni-Oliveira (2007, p. 15) assim a conceituam:

A Climatologia constitui o estudo científico do clima. Ela trata dos padrões de comportamento da atmosfera em suas interações com as atividades humanas e com a superfície do planeta durante um longo período de tempo. Esse conceito revela a ligação da Climatologia com a abordagem geográfica do espaço terrestre, pois ela se caracteriza em um campo do conhecimento no qual as relações entre sociedade e natureza configuram-se como pressupostos básicos para a compreensão das diferentes paisagens do planeta e contribui para uma intervenção mais consciente na organização do espaço.

Partindo desse pressuposto infere-se que essa ciência é de natureza complexa. Em função disso, ensinar climatologia requer um maior entendimento por parte dos professores, pois os conteúdos abordados fazem parte do nosso cotidiano em virtude da repercussão dos fenômenos climáticos no ambiente, além da difusão destes por inúmeras fontes como: televisão, jornais, 
revistas, livros entre outros, e pelo seu próprio enfoque atual de mudanças climáticas e fenômenos como o Aquecimento Global, Efeito Estufa, Ilhas de Calor, etc.

Quando falamos em construção do conhecimento de climatologia na geografia e o que a mesma engloba, o livro deve ser visto somente como um complemento na construção e desenvolvimento da aprendizagem do aluno, pois o processo de construção do conhecimento climatológico deve ser através da relação entre o cotidiano e os conceitos científicos. Desse modo, a construção do conhecimento ocorre pela prática diária, fazendo observações e experiências deixando o aluno não apenas como observador e sim como parte integrante da construção do conhecimento.

Assim como outras disciplinas, a geografia, ainda, é ensinada nas escolas de uma maneira tradicional, baseando-se na memorização de nomes e fenômenos e nessa construção de saberes conceituais está o ensino de climatologia, que por sua vez é desvinculando da realidade dos alunos, fazendo que os próprios questionem o motivo de se estudar Geografia e seus conceitos.

É percebendo essas lacunas quanto a prática dos conteúdos, que o professor deve contextualizar os fatores naturais como parte da vida dos alunos, e que o homem é produto e produtor do espaço que está inserido e não somente um mero espectador. Azevedo et al (2011, p. 2) descreve que "a prática docente deve refletir uma geografia integrada em que a discussão da natureza ultrapasse a relação com recursos, sendo integrados diretamente com os aspectos práticos da vivência humana".

Os educadores nos dias atuais têm que pensar novas metodologias pedagógicas para mostrar aos alunos que o conhecimento geográfico é um instrumento social e que faz parte de sua realidade, estabelecendo assim uma relação entre o conteúdo e a realidade do aluno.

Acredita-se que a Climatologia Escolar deve ser ensinada de modo que os alunos entendam e compreendam esta ligação, e a utilização de materiais didáticos e práticas, além das quatro paredes de uma sala de aula, abrem um leque de possibilidades para que o aluno aprenda praticando e observando que os conceitos estão além de um papel, que os mesmos fazem parte de suas vidas. Assim os coloca como um elemento ativo na construção do conhecimento, levandoo a relacionar os fenômenos climáticos com sua realidade de forma crítica e reflexiva.

A importância da Climatologia no Ensino Fundamental vai muito além de um conhecimento abstrato e é essencial na concepção de um cidadão crítico e participativo na sociedade, pois os conceitos tratados pela Climatologia e inseridos na vida cotidiana dos estudantes são relevantes para explicação e a compreensão de fenômenos que atingem diretamente ou indiretamente sua vida. Castro (1997) afirma que abordar o conceito de clima é valorizar a capacidade de apreensão que os alunos têm com relação à importância do tempo na transformação do espaço geográfico.

Além do professor de geografia trabalhar com a relação teoria e prática, o mesmo também deve dominar o conteúdo que vai ensinar, para que assim o aluno seja mais participativo nas aulas. Pois a abordagem baseada apenas no uso exclusivo do livro didático, limitado a observações de 
gravuras, não permite ao aluno compreender de fato a proposta do conteúdo, sendo assim, é importante o trabalho com aulas práticas. A proposta de oportunizar a participação do aluno em sala é algo de grande importância para o seu aprendizado, como foi colocado por (CASTROGIOVANNI, 2007).

Para a formação dos estudantes, os conhecimentos e as aplicações da Climatologia são imprescindíveis em diversas áreas de conhecimento como a saúde, planejamento urbano e territorial, agricultura, turismo, entre outros, o que reforça os laços da necessidade de uma Climatologia que se apodere de situações cotidianas para explicar e analisar os fenômenos atmosféricos de forma a se inserir na realidade dos estudantes.

Por tudo quanto aludido, observa-se que faz-se necessário o uso de diversas práticas que viabilize um ensino contextualizado e integrado. Pensa-se, assim, que a realização de atividades práticas pode ser uma ferramenta didática capaz de aproximar a climatologia escolar da realidade dos discentes, tornando o ensino de Geografia mais dinâmico.

\section{Resultados e Discussões}

Para o procedimento lógico de aplicação da aula utilizou-se materiais de fácil compreensão e acesso, que podem criar uma prática de ensino/aprendizagem particular, compondo tanto a teoria como a prática relacionando os diferentes aspectos climáticos, a relação com o meio ambiente trazendo, assim, uma discussão e uma leitura dos fenômenos atmosféricos.

Dessa maneira buscando tornar as aulas mais interativas propomos para professor e alunos trabalhar com a confecção de instrumentos climatológicos, usando materiais recicláveis tais como: papelão, copos descartáveis, canudos, potes de maionese, tubos de linhas de costura, balões entre outros e assim por meio da produção desses materiais didáticos, analisar os aspectos climáticos de forma prática no espaço escolar.

Na primeira atividade apresentamos vários instrumentos usados para trabalhar climatologia no ensino de geografia, suas funções e importância. Com os alunos produzimos um barômetro feito de frasco de maionese, bexiga, canudo de refresco, barbante, régua, caixa de papelão e cola como mostra a figura 1. 


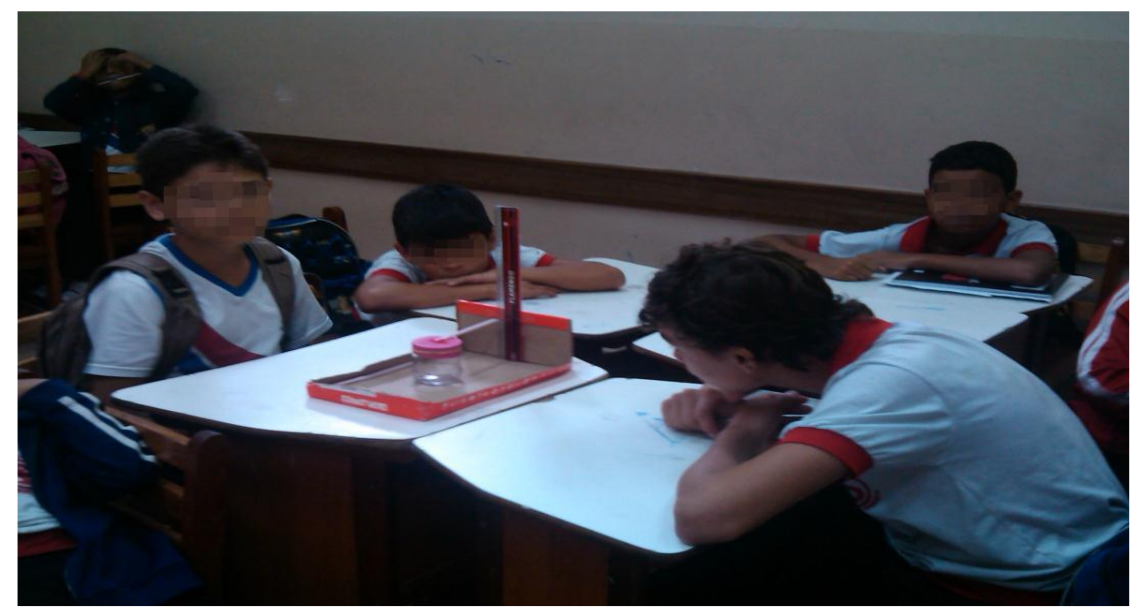

Figura 1: Alunos analisando o material didático: Barômetro

Na prática os alunos observaram as variações da pressão exercida pela atmosfera e de que maneira ela pode variar para um tempo bom (estável) ou ruim (instável). Em uma explicação simples discorremos que quando diminuir a pressão atmosférica ambiente, o ar aprisionado no interior do vidro por ter pressão maior, forçará a membrana para fora e o ponteiro baixa na escala, quando a pressão diminuir o ponteiro (o canudo) baixará, Baixa Pressão = Tempo "ruim". Quando aumentar a pressão, o ponteiro subirá Alta Pressão = Tempo "Bom".

Esse tipo de abordagem prática no ensino de climatologia é de fundamental importância, pois desperta nos alunos um maior interesse pelos conteúdos ministrados e os interliga de forma direta, provocando $o$ ato de refletir os aspectos climáticos que os rodeiam com os conteúdos ministrados em sala de aula.

Outro fato observado foi o fortalecimento do vínculo docente e discente, bem como a maior interação entre os próprios alunos mediante ao trabalho em equipe. É nessa perspectiva que Monteiro (2009, p. 02) discorrer que:

[...] no estudo do clima, esses procedimentos são essenciais, devido à dificuldade de esclarecer ao aluno pontos importantes sobre este assunto e ainda associá-los a outros aspectos, sendo necessário criar ferramentas capazes de trazer para a sala de aula mais estratégias dinâmicas, levando o aluno a ser um agente ativo no processo de ensino-aprendizagem, o qual vai descobrir novas possibilidades de análise, observando e compreendendo a dinâmica climática, em suas várias escalas.

Em outra atividade conjunta com os alunos elaboramos um novo instrumento climático, o anemômetro no qual utilizamos como materiais: copos pequenos de plásticos, lápis, borracha, tiras de papelão, pregos, tachinhas, fita gomada, tubinhos feito de papel e suporte feito de pedaços de papelão, de acordo com a figura 2. 


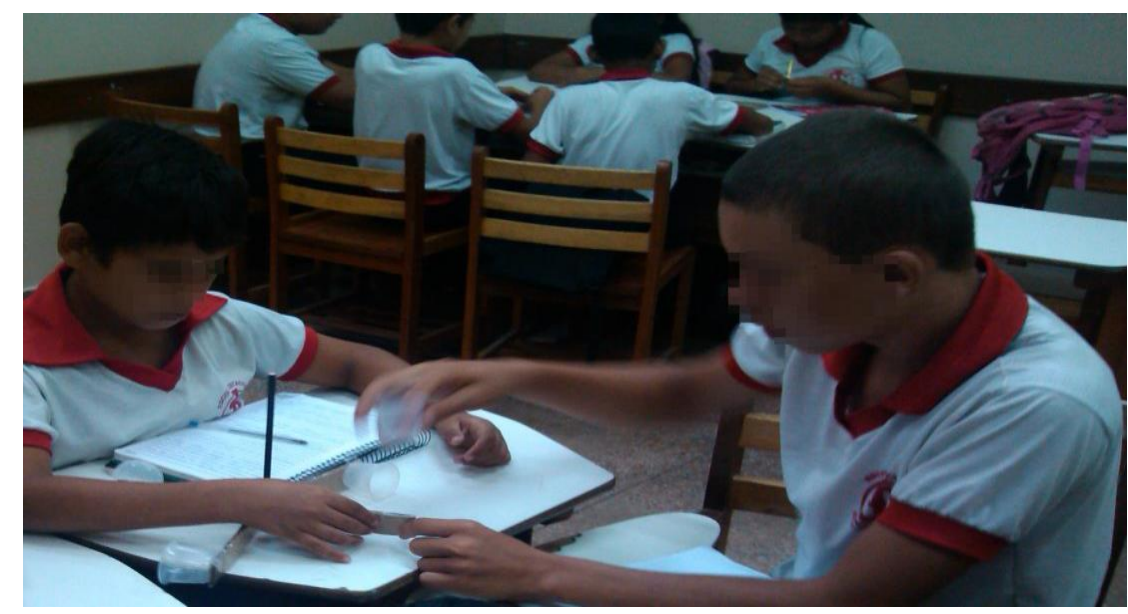

Figura 2: Construção do material didático: Anemômetro

$\mathrm{Na}$ prática os discentes montaram seus instrumentos em grupos tendo a oportunidade de aprender sobre a importância do aparelho para verificação da direção do vento, da velocidade entre outros fatores presentes na climatologia tais como: massas de ar, monções de ventos, tempestades, furacões etc.

As diferentes formas de abordagens práticas com os alunos despertaram a curiosidade e o interesse pelos conteúdos repassado, segundo Vasconcellos (2008, p.127): "Não queremos um aluno conformista, passivo, sem questionamento. Desejamos que ele possa não só adquirir conhecimento, mas ser capaz de produzi-lo".

Observou-se que através de uma proposta prática houve maior interação dos alunos em grupos, tornando o trabalho dos mesmos mais produtivos, além de despertar uma curiosidade em montar os instrumentos e observa-los em ação. Dessa maneira estimulamos tanto os discentes como o docente a transformar teorias em práticas, retirando o foco do livro didático como o único mediador do conhecimento e sendo utilizado como sua função, ou seja, apena como um auxiliador.

Segundo Araújo (2006), a mediação do processo de ensino-aprendizagem através de atividades prática, ainda é agente de discussão para os envolvidos. De maneira que é importante observar a questão da formação do professor, o qual deve ser preparado e qualificado para aplicar novas formas e ferramentas de ensino no âmbito escolar atual.

Trabalhar com os alunos de forma prática através de uma percepção do conhecimento teórico adquirido pelos mesmos e fazendo uma junção com seu dia-a-dia é extremamente importante e eficaz para a compreensão e interpretação, não somente como um modo dinâmico de ensino, mas também possibilitando melhorias no processo de ensino-aprendizagem mediante a participação ativa do educando como do educador.

Porém, observou-se também uma grande dificuldade na compreensão e na aplicabilidade da climatologia pelos alunos e pelo professor, uma vez que os conteúdos abordados de forma somente abstrata dificultam o processo da aprendizagem. 
Dessa maneira através das experiências aplicadas demonstramos que a produção prática de instrumentos climáticos para o ensino da climatologia é de fundamental relevância, contribuindo para estabelecer uma relação mais concreta entre o cotidiano e a teoria aplicada na sala de aula, além de que, estas experiências despertaram o interesse dos alunos pela disciplina de geografia.

De acordo os comentários dos discentes constatamos que atividades ministradas de formas diferentes da geografia tradicional levam aos alunos a uma nova percepção sobre mudanças e variações do tempo que até então os mesmos não compreendiam por serem repassadas na perspectiva da educação bancária.

De acordo com o relato dos alunos J.C e B.S, tanto o Barômetro como o Anemômetro, trouxeram uma nova dinâmica para as aulas de climatologia, estimulando a participação e o interesse sobre os assuntos climáticos (figura 3), como observado na fala do aluno J.C "Foi legal participar das aulas de geografia e produzir os aparelhos e entender quando a pressão tá baixa ou alta num local e sobre a importância dos ventos, devia ter mais aulas assim. Eu ia gostar".

A despeito disso Zabala (1998, p.75) argumenta que o papel do professor adquire todo sentido, como favorecedor e dinamizador de todo o processo, estabelecendo os desafios individuais e coletivos e oferecendo meios que mantenham a atenção dos alunos.

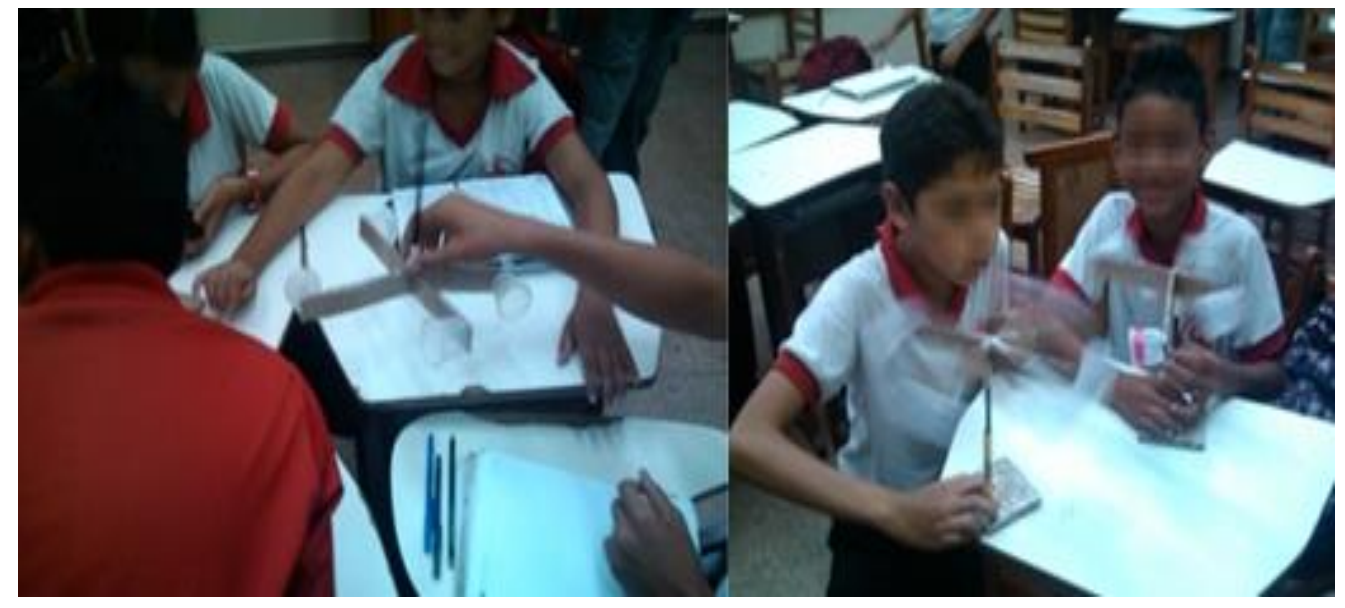

Figura 3: Alunos construindo o material didático: Anemômetro

Os trabalhos práticos segundo Neves e Sousa (2010) são uma boa maneira de exercitar as ideais dos alunos, transpondo a responsabilidade de análise para os alunos. Os trabalhos práticos com instrumentos didáticos estabelecem uma relação com o conteúdo e vivência, pois deixa a possibilidade de análise para os alunos, exercendo assim um papel ativo no ensino, notando aplicação do conhecimento adquirido na pratica.

A partir da percepção de uma aula prática os alunos compreenderam melhor os aspectos climáticos como, por exemplo, identificação dos ambientes mais quentes e frios, as variações de pressão atmosférica por meio do barômetro produzido em sala, as massas de ar, como os ventos 
influenciam na variação do clima, a velocidade do vento utilizando o anemômetro criado por eles, as diferenças simples que ocorrem em microclimas a macro climas e que estão presentes no diaa-dia de cada um deles.

Notou-se, que os discentes apresentaram curiosidades aguçadas nas experiências aplicadas, argumentavam, interagiram com os conteúdos repassados e demonstravam um interesse maior pela disciplina geográfica.

Os experimentos que foram relatados ao longo do trabalho, demonstraram a importância de uma aula diferenciada para o ensino de climatologia, pois criaram novas condições de interações entre o professor e o aluno, de maneira que ambos mesclam seus conhecimentos e reconhecemse como partes de um todo.

Como se fez notar os alunos despertam suas curiosidades para a construção de novos conhecimentos e descobertas não somente no ensino da climatologia, mas dos demais conteúdos que englobam a geografia atual. Esses exercícios práticos aplicados na aula de climatologia não podem ser menosprezados na prática de ensino do Professor de Geografia, que muitas vezes passam despercebidos durante a graduação, gerando e eternizando duvidas e vícios que os levam a um ensino tradicional.

\section{Considerações Finais}

A partir desta atividade prática, observou-se que a utilização e construção de materiais didáticos (recicláveis) relacionados aos conteúdos de clima possibilitou maior e melhor entendimento dos fenômenos climáticos pelos discentes.

A construção dos materiais didáticos (anemômetro e barômetro) despertou o interesse dos alunos pelos conteúdos trabalhados. Além disso, constatou-se que os discentes conseguiram relacionar tais conteúdos com o seu cotidiano, levando-nos a reafirmar que a Geografia Atual trabalha nessa perspectiva.

Essa prática proporcionou uma interação satisfatória entre professor e alunos, favorecendo o processo de ensino-aprendizagem. Sendo assim, o professor exerce um papel fundamental na construção do saber, buscando transformar as complexidades, em especial no caso da Climatologia, em aulas mais interativas e esclarecedoras.

\section{Referências}

AZEVEDO, A. K. A.; COSTA, F. F.; ARAÚJO JÚNIOR, A. C. R. A. O ensinar da geografia física no ensino fundamental: aplicação didática dos movimentos de massa através da utilização de maquetes. In: SIMPÓSIO BRASILEIRO DE GEOGRAFIA FÍSICA APLICADA, 14. 2011, Dourados-MS. Anais... Dourados: UFDG, 2011. 
ARAÚJO, E. D. A escola do século XXI e as novas tecnologias da informação e da comunicação. TV Escola, 2006.

CASTROGIOVANNI, A. C. Para entender a necessidade de práticas prazerosas no ensino de geografia na pós-modernidade. In: REGO, Nelson; CASTROGIOVANNI, A.C; KAERCHER, N.A. Geografia. Porto Alegre: Artmed, 2007.

CASTRO, M. G. S. A Climatologia e os professores de Geografia do 1e e 2 graus. Anais do VII Simpósio Brasileiro de Geografia Física Aplicada e I Fórum Latino-Americano de Geografia Física Aplicada. Curitiba: UFPR, 1997.

MENDONÇA, Francisco; DANNI-OLIVEIRA, Inês Moresco. Climatologia: Noções básicas e climas do Brasil. São Paulo: Oficina de textos, 2007. 200 p.

MONTEIRO, J. B.; FARIAS, J. F., ZANELA, M. E. O uso dos recursos didáticos com base nas tecnologias de informação e comunicação no ensino da climatologia. In: ENCONTRO DEGEÓGRAFOS DA AMÉRICA LATINA, 11, 2009. Resumo... Montevideo, Uruguai, 2009.Disponível em: $<$ http/egal12009.easyplanners.info>.

NEVES, S. R. A.; SOUSA, C. C. A. A importância de trabalhos práticos no ensino de climatologia do 60 ao 9o Ano do ensino fundamental. In: SIMPÓSIO BRASILEIRO DE CLIMATOLOGIA GEOGRAFICA, 9. 2010. Fortaleza-CE. Anais... Fortaleza: UFC e ABClima, 2011.

OLIVEIRA, D.J.L.; CHAGAS, F. L. R.; ALVES, W. S.. Os desafios de ensinar a climatologia nas escolas. In: II Congresso De Educação-UEG/UNU-Unidade De Iporã. A Formação de Professores: uma proposta de pesquisa a partir da reflexão sobre a prática docente. Anais...2012. p. 47-51.

VASCONCELOS, Laura Cristina da Silva. A Construção De Instrumentos Meteorológicos Como Prática Didática Da Climatologia No Ensino Fundamental. Revista Geonorte, Edição Especial 2, V.1, N.5, p.34 45, 2012.

ZABALA, Antoni. A prática educativa: como ensinar; tradução Ernani F. da F. Rosa - Porto Alegre: Artmed, 1998. 